\title{
A DNA-binding protein containing two widely separated zinc finger motifs that recognize the same DNA sequence
}

\author{
Chen-Ming Fan and Tom Maniatis \\ Department of Biochemistry and Molecular Biology, Harvard University, Cambridge, Massachusetts 02138 USA
}

\begin{abstract}
We have isolated a full-length cDNA clone encoding a protein (PRDII-BF1) that binds specifically to a positive regulatory domain (PRDII) of the human IFN- $\beta$ gene promoter, and to a similar sequence present in a number of other promoters and enhancers. The sequence of this protein reveals two novel structural features. First, it is the largest sequence-specific DNA-binding protein reported to date $(298 \mathrm{kD})$. Second, it contains two widely separated sets of $\mathrm{C}_{2}-\mathrm{H}_{2}$-type zinc fingers. Remarkably, each set of zinc fingers binds to the same DNA sequence motif with similar affinities and methylation interference patterns. Thus, this protein may act by binding simultaneously to reiterated copies of the same recognition sequence. Although the function of PRDII-BF1 is not known, the level of its mRNA is inducible by serum and virus, albeit with different kinetics.
\end{abstract}

[Key Words: DNA-binding protein; IFN- $\beta$ gene; $\mathrm{H}-2 \mathrm{~K}^{\mathrm{b}}$ gene; serum induction; virus induction]

Received September 26, 1989; revised version accepted October 31, 1989.

The human interferon $\beta$ (IFN- $\beta$ ) gene is highly inducible by virus or synthetic double-stranded RNA (poly[r(I-C)]) (for review, see De Maeyer and De Maeyer-Guignard 1988). Characterization of the regulatory sequences required for induction led to the identification of two distinct positive regulatory domains within the IFN- $\beta$ gene promoter (PRDI and PRDII; Goodbourn and Maniatis 1988; Keller and Maniatis 1988). Synthetic oligonucleotides containing a single copy of PRDI or PRDII do not display transcriptional activity, but oligonucleotides containing one copy each of the two elements or two copies each of PRDI or PRDII function as constitutive and virus-inducible regulatory elements /Goodbourn and Maniatis 1988; Fan and Maniatis 1989; Fujita et al. 1989a; Visvanathan and Goodbourn 1989).

PRDI and PRDII interact with different sets of specific DNA-binding proteins (Keller and Maniatis 1988). At present, five different PRDI-binding factors have been identified. PRDI-BFc is a factor present in nuclear extracts prepared from uninduced and induced human MG63 cells (an osteosarcoma line; Keller and Maniatis 1988). PRDI-BFi is a virus-inducible binding activity detected in nuclear extracts from induced MG63 cells (Keller and Maniatis 1988). This factor, which is not detected in extracts from uninduced cells, is activated in the absence of protein synthesis. IRF-1 is a PRDI-binding activity that is present in extracts of uninduced and virus-induced mouse L929 cells (Fujita et al. 1988). The level of this factor does not change significantly on viral induction. A cDNA clone thought to encode IRF-1 has been isolated and characterized (Miyamoto et al. 1988). When this clone is expressed at high levels in monkey
COS cells, expression of the endogenous IFN- $\alpha$ and IFN- $\beta$ genes is observed (Fujita et al. 1989b). However, like IRF-1, the protein encoded by this gene has not yet been shown to respond to viral induction. PRDI-BF1 is a protein encoded by a cDNA clone isolated from a cDNA library of MG63 cell mRNA (A. Keller and T. Maniatis, unpubl.). IBF-1 is a $\gamma$-interferon (IFN- $\gamma$ ) inducible nuclear factor detected in $\mathrm{HeLa}$ cell nuclear extracts (Blanar et al. 1989). Although all of these factors bind specifically to PRDI, it is not known which (if any) are involved in IFN- $\beta$ gene regulation.

A number of factors have also been shown to bind to PRDII. PRDII-BF was initially identified in nuclear extracts from both uninduced and virus-induced human MG63 and HeLa cells (Keller and Maniatis 1988 and unpubl.). EBP1 is a $57-60-\mathrm{kD}$ nuclear protein purified from uninduced HeLa cells /Clark et al. 1988; Clark and Hay 1989). This factor was originally identified by its ability to bind to a specific region of the SV40 enhancer core. NF- $\mathrm{BB}$ is a $45-50-\mathrm{kD}$ virus-inducible factor that is sequestered in the cytoplasm before induction and is translocated into the nucleus on viral treatment in a variety of cell types tested (Lenardo et al. 1988, 1989, Hiscott et al. 1989; Visvanathan and Goodbourn 1989). NF- $k \mathrm{~B}$ is the only PRDII-binding protein that has been implicated in IFN- $\beta$ gene regulation. These observations reveal that many different proteins can bind to the same DNA sequence. However, it should be stressed that the functional significance of these interactions (if any) has not been established.

To obtain cDNA clones that encode factors that bind specifically to PRDII, we screened a $\lambda g t 11$ cDNA expres- 
sion library with an oligonucleotide containing multiple copies of PRDII (Singh et al. 1988; Vinson et al. 1988). A cDNA clone designated PRDII-BF1 was isolated, characterized, and shown to be identical to previously reported cDNA clones designated human immunodeficiency virus type 1 enhancer-binding protein (HIV-EP1; Maekawa et al. 1989) and major histocompatibility complex (MHC)-binding protein-1 (MBP-1; Singh et al. 1988; A.S.Baldwin et al., pers. comm.). The protein encoded by these cDNA clones was shown to bind specifically to the HIV-1 enhancer, the promoter of the MHC H2-K ${ }^{b}$ gene, and to a similar site within the immunoglobulin $\kappa$ gene $(\mathrm{Ig}-\kappa)$ enhancer. All of these sites also bind to NF-kB.

In this paper we show that the full-length cDNA clone of PRDII-BF1 has a single open reading frame (ORF) of 8151 nucleotides, which encodes a protein of 2717 amino acids - corresponding to a molecular mass of 298 $\mathrm{kD}$. Examination of the DNA sequence reveals that the encoded protein contains two sets of two zinc finger $(\mathrm{Zn}$ finger) motifs separated from each other by 1630 amino acids. When expressed individually in bacteria, either set of $\mathrm{Zn}$ fingers is capable of binding to both PRDII and $\mathrm{H}-2 \mathrm{~K}^{\mathrm{b}}$ sequences, but with approximately fivefold higher affinity to the latter site. An additional $\mathrm{Zn}$ finger motif of the C-C- $\mathrm{X}_{13}-\mathrm{H}-\mathrm{C}$ type is located between these two sets of $\mathrm{Zn}$ fingers, but its DNA recognition sequence, if any, has not been identified. Although function of PRDII-BF1 is not known, its unusual structure suggests that it may act by simultaneously binding to reiterated copies of the same recognition sequence.

\section{Results}

Cloning and characterization of a full-length PRDIIBF1 cDNA

A $\lambda$ gt 11 cDNA expression library prepared from MG63 cell mRNA was screened with a ${ }^{32} \mathrm{P}$-labeled oligonucleotide probe containing multiple copies of the PRDII sequence (Fig. 1; Fan and Maniatis 1989), using methods developed by Singh et al. (1988) and Vinson et al. (1988). Initially, a phage clone containing a $0.95-\mathrm{kb}$ cDNA insert was obtained ( $\lambda \mathrm{G} 3.4$; Fig. 1). Bacterial cell extracts prepared from IPTG-induced $\lambda$ G3.4 lysogens contained a specific PRDII-binding activity (data not shown).

To determine the relationship between the cDNA insert in $\lambda$ G3.4 and the mRNA from which it was derived, we hybridized an RNA blot of MG63 cell mRNA with the labeled cDNA clone. A single band was observed corresponding to an mRNA of $\sim 9.5 \mathrm{~kb}$ (data not shown). To obtain a full-length cDNA clone, we screened MG63 and HL-60 cell cDNA libraries using the $\lambda \mathrm{G} 3.4 \mathrm{cDNA}$ as a hybridization probe. We obtained several overlapping cDNA clones that, together, span $>7.1 \mathrm{~kb}$ of contiguous cDNA sequence (Fig. 1). An oligonucleotide corresponding to a sequence near the $5^{\prime}$ end of the $\lambda \mathrm{H} 122$ cDNA clone was then used to prime the synthesis of a cDNA clone from MG63 cell poly $(\mathrm{A}){ }^{+}$RNA (Polites and Marotti 1986). A 2.1-kb cDNA clone was obtained ( $\lambda$ MG71; Fig. 1), which contains the $5^{\prime}$ end of an ORF encoding 592 amino acids. Nucleotide sequence analyses of the entire set of overlapping cDNA clones reveals that the ORF in $\lambda M G 71$ continues through the $3^{\prime}$-most cDNA clones $\lambda \mathrm{H} 9$ and $\lambda \mathrm{H} 10$ (Fig. 1).

RNA blotting and RNase protection experiments with hybridization probes spanning the entire length of the cDNA indicated that the cloned sequences are contiguous in cellular mRNA. The total number of bases represented in the series of overlapping cDNA clones diagrammed in Figure 1 is 9015, very close to the size of the mRNA that hybridizes to the cDNA clone $(9.5 \mathrm{~kb})$.

To determine the size of the protein encoded by the full-length PRDII-BF1 cDNA, we determined the complete nucleotide sequence of a set of overlapping clones (Fig. 2). The sequence reveals an ORF of 8151 nucleotides, corresponding to a polypeptide chain of $298 \mathrm{kD}$. The cDNA clone contains 324 and 540 nucleotides of $5^{\prime}$ and $3^{\prime}$-untranslated sequence respectively. The $5^{\prime}$-untranslated region is highly GC rich $180 \%$ GC content within the first 250 nucleotides), and contains a rather weak fit to the consensus translational start signal (Kozak 1987). The 3'-untranslated sequence contains a weak AAUAAA polyadenylation signal and several stretches of AU-rich sequences, one of which is similar to the AUUUA mRNA destabilizer motif described by Shaw and Kamen (1986).

Examination of the encoded amino acid sequence reveals two sets of two $\mathrm{C}_{2}-\mathrm{H}_{2}$-type $\mathrm{Zn}$ finger motifs (for review, see Klug and Rhodes 1987; Evans and Hollenberg 1988). One set (fingers 1 and 2 ) is located within $\lambda M G 71$, whereas another set is present in $\lambda$ G3.4 in the same ORF (fingers 3 and 4). The two sets of $\mathrm{Zn}$ fingers are separated by 1630 amino acids (Figs. 1 and 2). An alignment of the sequences of the four $\mathrm{Zn}$ fingers with a consensus sequence is presented in Figure 3 (for review, see Klug and Rhodes 1987; Gibson et al. 1988). An acidic-amino acid-rich domain is located immediately downstream from fingers 3 and 4 . This region of 21 amino acids has a charge of -15 , suggesting that it may be an acidic transcription activation domain (Fig. 2; Ptashne 1988).

An additional $\mathrm{Zn}$ finger motif was identified in the region between the two sets of two $\mathrm{Zn}$ fingers (amino acids 955-981). This domain (finger 5) displays a C-C- $\mathrm{X}_{13}-\mathrm{H}-\mathrm{C}$ array, which was found previously in Xfin and SWI5 finger proteins (for review, see Klug and Rhodes 1987). As shown in the sequence alignment of Figure 3, the phenylalanine and leucine residues that are normally present within the finger domain at conserved positions of the consensus sequence are substituted by tyrosine and phenylalanine residues, respectively.

The NBRF 'DNA sequence data base /updated June 1989) was searched for additional sequence similarities, but no significant matches were obtained.

\section{Each set of the two $\mathrm{C}_{2}-\mathrm{H}_{2}$-type $\mathrm{Zn}$ fingers binds specifically to PRDII}

Alignment of the amino acid sequences of the two $\mathrm{Zn}$ fingers within each set reveals only $\sim 30 \%$ homology 


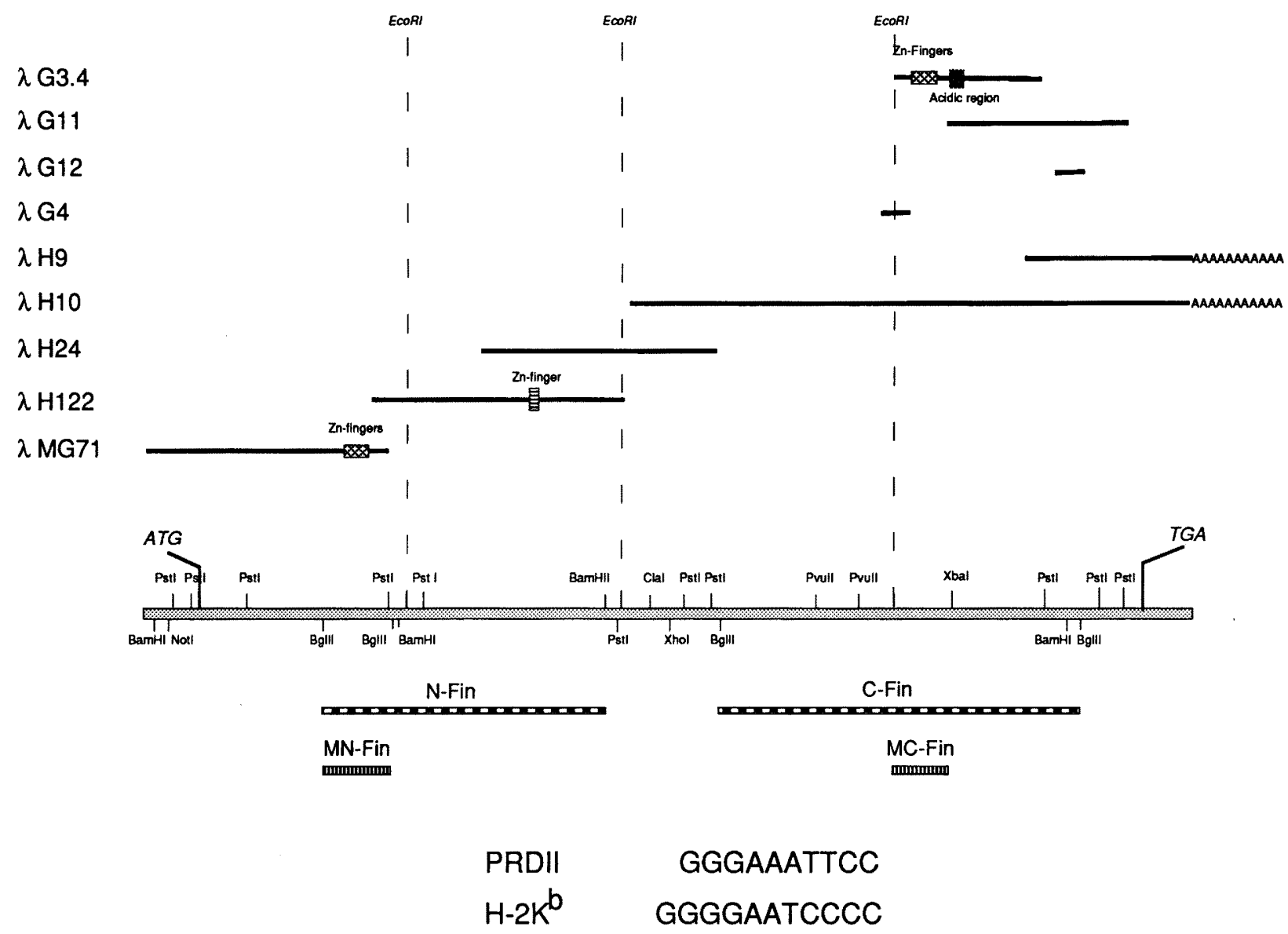

Figure 1. A diagram showing a set of overlapping CDNA clones containing the full-length PRDII-BF1 sequence. The black bars correspond to the length of each cDNA clone and the name of each clone is indicated on the side of the figure. Clones with poly A tail are marked AAAAAAAA at the end. the position of the single C-C-X $\mathrm{X}_{13}-\mathrm{H}-\mathrm{C} \mathrm{Zn}$ finger motif. The box, shows the location of an acidic amino acid-rich domain. The vertical dashed lines marked EcoRI show the internal EcoRI restriction sites within PRDII-BF1 cDNA. The $\%$ bar shows a partial restriction enzyme map of the full length cDNA clone, with the initiation and stop codon (ATG and TGA) indicated. The 10

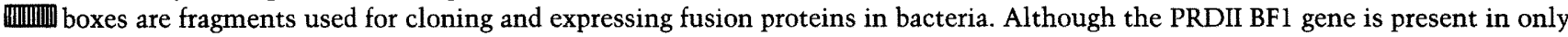
one copy in the human genome, some evidence suggests that at least two different types of PRDII-BF1 mRNA are produced in MG63 cells. One phage clone $\lambda M G 11$ (data not shown) contains a 5 '-noncoding sequence that differs from that of $\lambda M G 71$, and RNase mapping experiments indicate that the two different types of mRNA are present in total MG63 cell RNA. The same initiation codon is present in both types of mRNA, since the two sequences diverge within the 5 '-untranslated region of the mRNA (nucleotide 220 in Figure 2). At present, we do not know whether these two forms of mRNA are produced through alternative splicing or transcription initiation from different promoters, or both.

(Fig. 3); however, when aligned as sets of two, the sequences are $\sim 70 \%$ similar (Fig. $4 \mathrm{~A}$ ). The 4 amino acids adjacent to the first cysteine residue of each set of two $\mathrm{Zn}$ fingers are identical, and 5 out of 7 residues in the linker region between the two fingers are the same. In addition, a high degree of similarity is apparent in the His-His 'knuckles', and the tip of the second finger of each set. Finally, a cysteine residue is present within the Cys-Cys loop of both fingers 1 and 3 at a position where a phenylalanine is usually found (shown in Fig. 4A). This striking similarity of amino acid sequences of the two sets of fingers suggests that if they are DNA-binding motifs, they may recognize the same DNA sequence.

To test this possibility, we expressed proteins containing either set of $\mathrm{Zn}$ fingers separately in bacteria using a bacteriophage T7 expression system /Studier and Moffatt 1986). The cDNA fragments used to produce fusion proteins containing the amino-terminal set of $\mathrm{Zn}$ fingers (N-Fin) or the carboxy-terminal set (C-Fin) are diagrammed in Figure 1. As shown in Figure 4B, both the $\mathrm{N}$-Fin and the C-Fin proteins can, indeed, bind to PRDII within a DNA fragment from the IFN- $\beta$ promoter (IRE, Goodbourn et al. 1985) and to the $\mathrm{H}-2 \mathrm{~K}^{\mathrm{b}}$ recogniton sequence. Several protein-DNA complexes were observed, presumably attributable to the presence of partially digested protein in the bacterial extracts. Only the major complexes (indicated by arrows) were characterized further by methylation interference studies.

DNA-binding experiments indicate that both the carboxy- and amino-terminal $\mathrm{Zn}$ finger proteins have a 


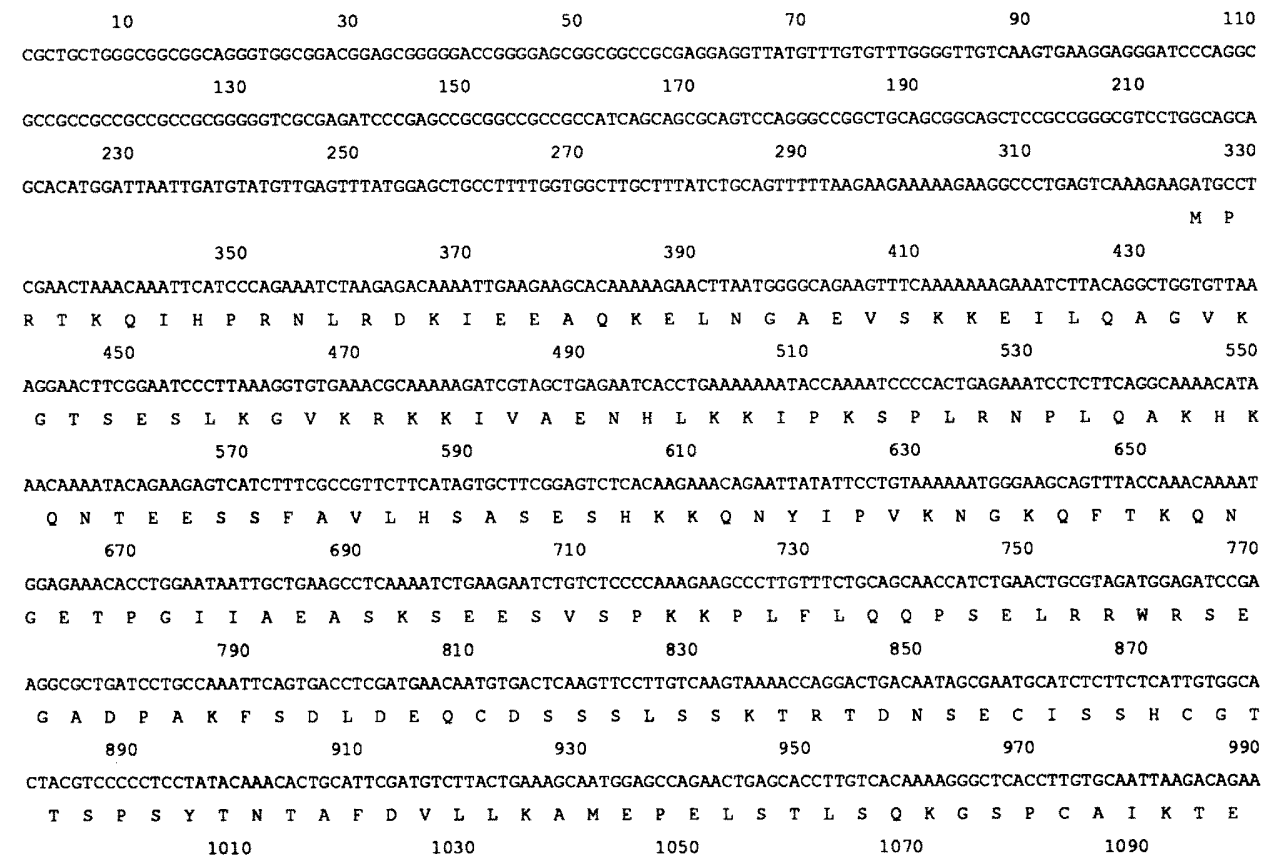
AAACTGAGGCCAAATAAAACTGCACGTTCCCCTCCCAAATTAAAAAACAGTTCAATGGATGCCCCAAATCAGACTTCACAGGAATTGGTTGCTGAATCACAGTCTTCTTG

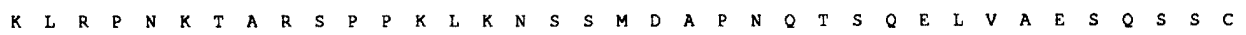
$1110 \quad 1130 \quad 1150 \quad 1170 \quad 1190 \quad 1210$ TACCTCATACACAGTCCATATGTCTGCTGCTCAGAAGAATGAGCAAGGGGCAATGCAGTCAGCTTCTCATT TGTATCATCAACATGAACACTTTGTTCCCAAATCCAACC T S Y T T V H M S A A $Q$ O K K N E $1230 \quad 1250 \quad 1270 \quad 1290 \quad 1310$ AACATAATCAACAGCTTCCGGGGTGTTCAGGTTTCACAGGATCACTGACAAATCTGCAAAATCAAGAGAATGCCAAACTTGAACAGGTTTATAATATAGCAGTGACATCA H N $1330 \quad 1350 \quad 1370 \quad 1390 \quad 1410 \quad 1430$ TCTGTAGGCCTAACTTCACCTTCCAGTAGATCTCAGGTTACTCCTCAAAACCAGCAAATGGATTCTGCTTCACCTTTGTCAATAAGTCCGGCTAATTCTACACAGTCGCC $\begin{array}{llllllllllllllllllllllllllllllllllllll}S & V & G & L & T & S & P & S & S & R & S & Q & V & T & P & Q & N & Q & Q & M & D & S & A & S & P & L & S & I & S & P & A & N & S & T & Q & S & P\end{array}$ $1450 \quad 1470 \quad 1490 \quad 1510 \quad 1530$ CCCCATGCCAATCTATAATTCAACTCATGTTGCCTCTGTTGTYAATCAAAGCGTAGAGCAAATGTGCAATCTTCTTCTGAAAGATCAGAAGCCAAAAAAACAAGGAAAAT $\begin{array}{lllllllllllllllllllllllllllllllllllll}P & M & P & I & Y & N & S & T & H & V & A & S & V & V & N & Q & S & V & E & Q & M & C & N & L & L & L & K & D & Q & K & P & K & K & Q & G & K & Y\end{array}$ $1550 \quad 1570 \quad 1590 \quad 1610 \quad 1650$ ATATTTGTGAGTATTGCAATAGAGCATGTGCAAAGCCTAGTGTGCTTTTAAAGCATATCCGCTCCCACACTGGAGAGCGACCCTATCCCTGTGTGACT TGTGGATTTTCA

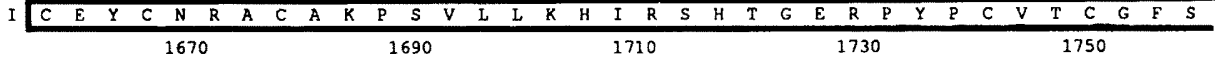

TTTAAGACTAAAAGTAATCTGTATAAGCACAAGAAATCCCACGCACATACTATCAAACTGGGTCTTGTCTTGCAACCAGATGCTGGTGGCTTGTTCTTGTCCCACGAGTC

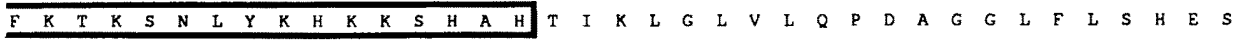
$1770 \quad 1790 \quad 1810 \quad 1830 \quad 1850 \quad 1870$ CCCCAAAGCACTTAGTATTCATTCAGACGTAGAAGACAGTGGGGAGAGCGAGGAGGAAGGCGCCACTGATGAGAGACAGCATGACCTGGGCGCCATGGAGCTGCAGAATG

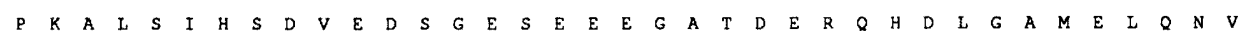
$1890 \quad 1910 \quad 1930 \quad 1950 \quad 1970$

TGCACATAATAAAGAGGATGTCAAATGCTGAAACTTTACTAAAATCAAGCTTCACTCCAAGCAGTCCAGAAAATGTGATAGGTGACTTTTTGCTACAGGACAGATCTGCA

$\begin{array}{llllllllllllllllllllllllllllllllllllll}H & I & I & K & R & M & S & N & A & E & T & L & L & K & S & S & F & T & P & S & S & P & E & N & V & I & G & D & F & L & L & Q & D & R & S & A\end{array}$ 1990 2010 2030 2050 2070 2090 GAATCACAAGCTGTGACAGAGTTACCGAAAGTTGTGGTCCACCATGTCACTGTGTCCCCCTTAAGAACTGACAGTCCAAAGGCCATGGATCCCAAGCCTGAACTTTCTAG

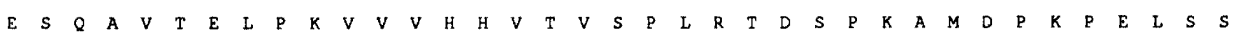
$2110 \quad 2130 \quad 2150 \quad 2170 \quad 2190$ TGCACAAAAGCAGAAGGACCTTCAGGTGACAAACGTACAGCCACTTTCAGCCAACATGTCCCAGGGTGGAGTCTCCAGGTTGGAGACTAATGAGAATTCCCACCAGAAAG $\begin{array}{llllllllllllllllllllllllllllllllllllll}\text { A } & Q & K & Q & K & D & L & Q & V & T & N & V & Q & \text { P } & \text { L } & S & A & N & M & S & Q & G & G & V & S & R & L & E & T & N & E & N & S & H & Q & K & G\end{array}$

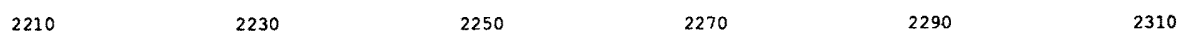
GCGACATGAATCCACTGGAAGGAAAGCAAGACTCTCACGTAGGAACGGTACACGCCCAGCTACAAAGGCAGCAGGCTACCGATTACTCCCAAGAGCAGCAAGGAAAGCTC

Figure 2. Complete cDNA and protein sequences of PRDII-BFl. The ORF begins at nucleotide 325 and ends at 8475 , thus encoding a protein of 2717 amino acids. The $\mathrm{C}_{2}-\mathrm{H}_{2}$-type $\mathrm{Zn}$ finger motifs are boxed with a solid line, and the single C-C- $\mathrm{X}_{13}-\mathrm{H}-\mathrm{C}$-type $\mathrm{Zn}$ finger motif is boxed with a dashed line. The acidic amino-acid rich domain is underlined. Figure 2 is continued on the following pages.

higher affinity for the $\mathrm{H}-2 \mathrm{~K}^{\mathrm{b}}$ site than for the IRE site. This conclusion is based on the fact that similar binding curves are observed with the two probes, even though the concentration of the IRE probe is five times higher than that of the $\mathrm{H}-2 \mathrm{~K}^{\mathrm{b}}$ probe (Fig. $4 \mathrm{~B}$ ). This observation is consistent with competition binding assays using oli- 


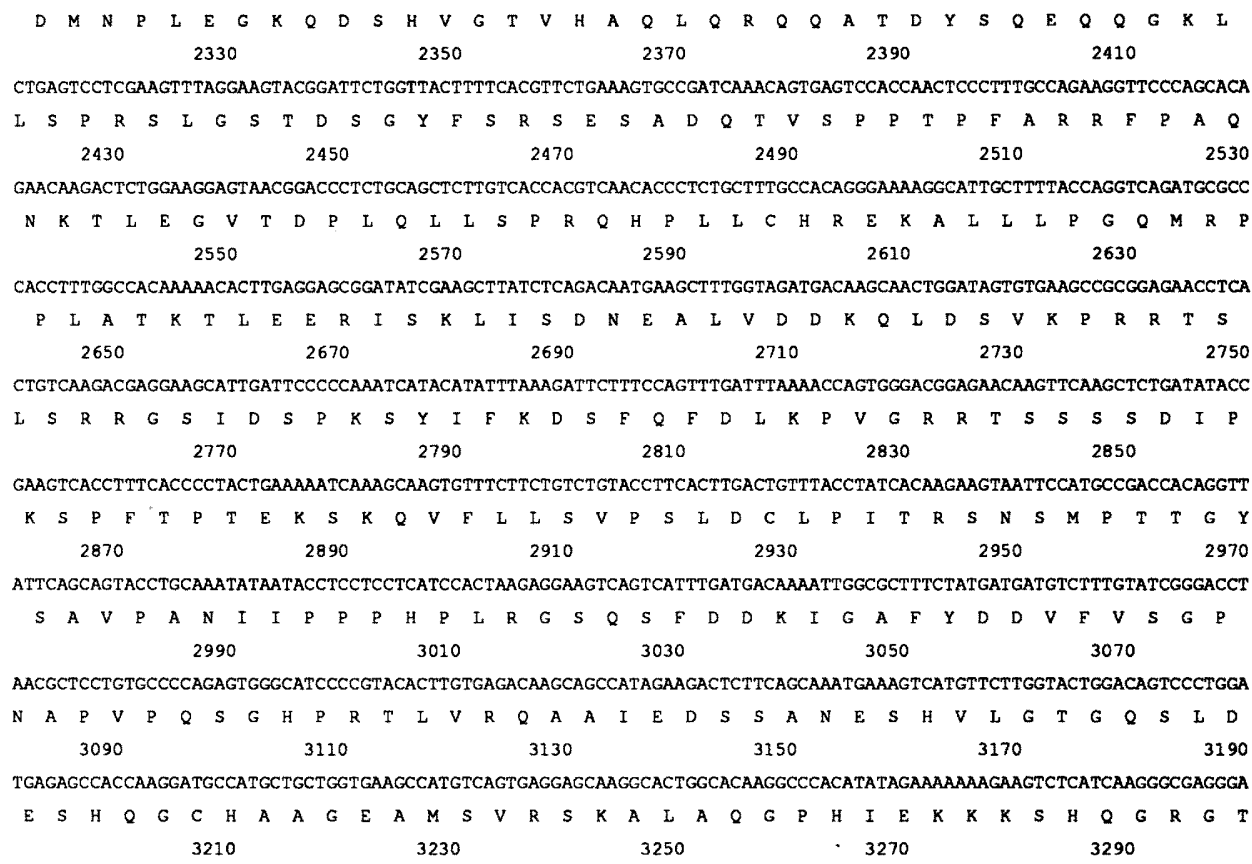

CAATGTTTGAGTGTGAAACTTGTAGAAACAGGTATAGGAAACTGGAAAATTTTGAAAATCATAAGAAATTTTACTGTTCTGAGTTACATGGACCAAAAACAAAGGTAGCC M F E ATGAGAGAACCTGAGCACAGCCCTGTGCCCGGCGGTCTGCAACCTCAGATTCTACACTACAGAGTCGCTGGGTCCTCCGGCATCTGGGAACAGACGCCCCAGATAAGAAA $\begin{array}{lllllllllllllllllllllllllllllllllllll}M & R & E & P & E & H & S & P & V & P & G & G & L & Q & P & Q & I & L & H & Y & R & V & A & G & S & S & G & I & W & E & Q & T & P & Q & I & R & K\end{array}$ $3430 \quad 3450 \quad 3470 \quad 3490 \quad 3510$

AAGGAGGAAAATGAAAAGTGTTGGGGATGATGAAGAACTTCAGCAAAATGAAAGTGGAACATCTCCAAAAAGTTCTGAAGGCCTTCAGTTTCAGAATGCTCTGGGCTGTA $\begin{array}{lllllllllllllllllllllllllllllllllllll}R & R & K & M & K & S & V & G & D & D & E & E & L & Q & Q & N & E & S & G & T & S & P & K & S & S & E & G & L & Q & F & Q & N & A & I & G & C & N\end{array}$ $\begin{array}{llllll}3530 & 3550 & 3570 & 3590 & 3610 & 3630\end{array}$ ATCCCAGTTTGCCTAAACATAGTGTTACCATAAGAAGTGACCAGCAGCATAAAAATATACAGTTGCAAAACTCCCATATTCACCTTGTTGCCAGGGGCCCTGAGCAGACC $\begin{array}{lllllllllllllllllllllllllllllllllllll}P & S & L & P & K & H & S & V & T & I & R & S & D & Q & Q & H & K & N & I & Q & L & Q & N & S & H & I & H & L & V & A & R & G & P & E & Q & T\end{array}$ $3650 \quad 3670 \quad 3690 \quad 3710 \quad 3730$ ATGGATCCCAAGCTGTCGACCATCATGGAACAACAGATAAGTTCAGCAGCCCAGGACAAGATAGAACTGCAGAGACACGGAACTGGAATCTCTGTCATCCAGCACACCAA

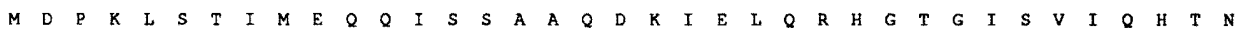
$\begin{array}{llllll}3750 & 3770 & 3790 & 3810 & 3830 & 3850\end{array}$ CTCCCTGAGCAGGCCCAACTCATTTGACAAGCCTGAGCCTTTTGAAAGAGCCTCCCCAGTTTCTTTCCAGGAGCTGAATAGAACGGGGAATTCCGGGTCTCTAAAAGTGA $\begin{array}{lllllllllllllllllllllllllllllllllllllll}S & L & S & R & \text { P } & N & S & F & D & K & P & E & P & F & E & R & A & S & P & V & S & F & Q & E & L & N & R & T & G & N & S & G & S & L & K & V & I\end{array}$ $387038390 \quad 3910 \quad 3930 \quad 3950$ TAGGAATCTCCCAAGAGGAAAGTCACCCTTCTCGGGACGGGTCTCATCCTCACCAGCTTGCACTATCAGACGCTCTCAGAGGAGAACTTCAGGAAAGCTCCAGAAAGAGT $\begin{array}{llllllllllllllllllllllllllllllllllll}G & I & S & Q & E & E & S & H & P & S & R & D & G & S & H & \text { P } & H & Q & L & A & L & S & D & A & L & R & G & E & L & Q & E & S & S & R & K & S\end{array}$ $3970 \quad 3990 \quad 4010 \quad 4030 \quad 4050 \quad 4070$ CCAAGTGAACGACATGTGTTAGGACAGCCCTCAAGACTTATCCGGCAGCACAACATCCAAGTTCCAGAGATTTTGGTCACAGAAGAACCAGATCGAGACCTGGAAGCTCA $\begin{array}{llllllllllllllllllllllllllllllllllllll}P & S & E & R & H & V & L & G & Q & P & S & R & \text { L } & I & R & Q & H & N & I & Q & V & P & E & I & I & V & T & E & E & P & D & R & D & L & E & A & Q\end{array}$ 1090 4110 4130 4150 4170 ATGCCATGATCAAGAAAAGTCAGAGAAGTTCAGTTGGCCCCAGCGTAGTGAAACCTTGTCAAAATTGCCAACAGAGAAACTGCCACCCAAAAAGAAAAGGCTCCGTCTGG

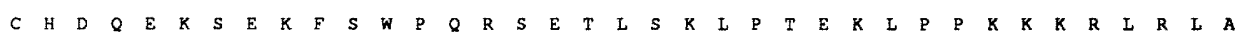
$4190 \quad 4210 \quad 4230 \quad 4250 \quad 4270 \quad 4290$ CTGAGATAGAACATTCCTCAACAGAATCGAGCTTTGATTCCACTCTCTCCAGGAGTCTAAGTAGGGAGAGCAGTTTATCTCACACTTCAAGTTTCTCAGCCTCTTTAGAC

$\begin{array}{lllllllllllllllllllllllllllllllllllll} & E & I & E & \text { H } & S & S & T & E & S & S & F & D & S & T & L & S & R & S & L & S & R & E & S & S & L & S & H & T & S & S & F & S & A & S & I & D\end{array}$ $4310 \quad 4330 \quad 4350 \quad 4370 \quad 4390$ ATAGAGGACGTTTCTAAAACGGAGGCTTCCCCCAAAATCGATTTTCTAAATAAAGCCGAGTTTCTTATGATTCCAGCTGGCTTGAATACTCTGAATGTTCCTGGATGTCA I $E \begin{array}{llllllllllllllllllllllllllllllllllll} & D & V & S & K & T & E & A & S & P & K & I & D & F & L & N & K & A & E & F & L & M & I & P & A & G & L & N & T & L & N & V & P & G & C & H\end{array}$ $4410 \quad 4430 \quad 4450 \quad-\quad 4470 \quad 450$ CCGGGAAATGAGGCGTACTGCATCAGAACAGATTAATTGCACGCAAACGTCAATGGAGGTCTCTGATCTCAGAAGCAAATCATTCGATTGTGGAAGCATCACCCCACCCC

Figure 2. (continued)

gonucleotides containing either two PRDII (PRDIIX2) or one $\mathrm{H}-2 \mathrm{~K}^{\mathrm{b}}\left(\mathrm{H}-2 \mathrm{~K}^{\mathrm{b}}\right)$ site as competitor (for DNA sequences, see Materials and methods). Approximately twice as much of the PRDIIX2 oligonucleotide is required for half-maximal competition compared to the
$\mathrm{H}-2 \mathrm{~K}^{\mathrm{b}}$ oligonucleotide, when the IRE probe is used in the gel retardation assay (Fig. 5A). Similar results were obtained when the $\mathrm{H}-2 \mathrm{~K}^{\mathrm{b}}$ fragment was used as a probe (Fig. 5B). Considering that the two oligonucleotides are approximately the same size and the PRDIIX2 oligo has 


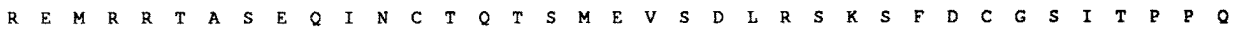

$$
\begin{aligned}
& 4530 \quad 4550 \quad 4570 \quad 4590 \quad 4610
\end{aligned}
$$

Figure 2. (continued)

two binding sites, we estimate that both $\mathrm{Zn}$ fingers bind to the $\mathrm{H}-2 \mathrm{~K}^{\mathrm{b}}$ site four to five times more tightly than to the PRDII site. The affinity of PRDII-BF1 for the PRDIIX2 probe is approximately the same as its affinity for the single copy of PRDII in the IRE, indicating that this protein does not bind cooperatively to the two PRDII sites in the PRDIIX2 probe (data not shown).

To determine whether either or both of the $\mathrm{Zn}$ finger motifs within the fusion proteins are sufficient for specific DNA binding, we carried out gel retardation assays 


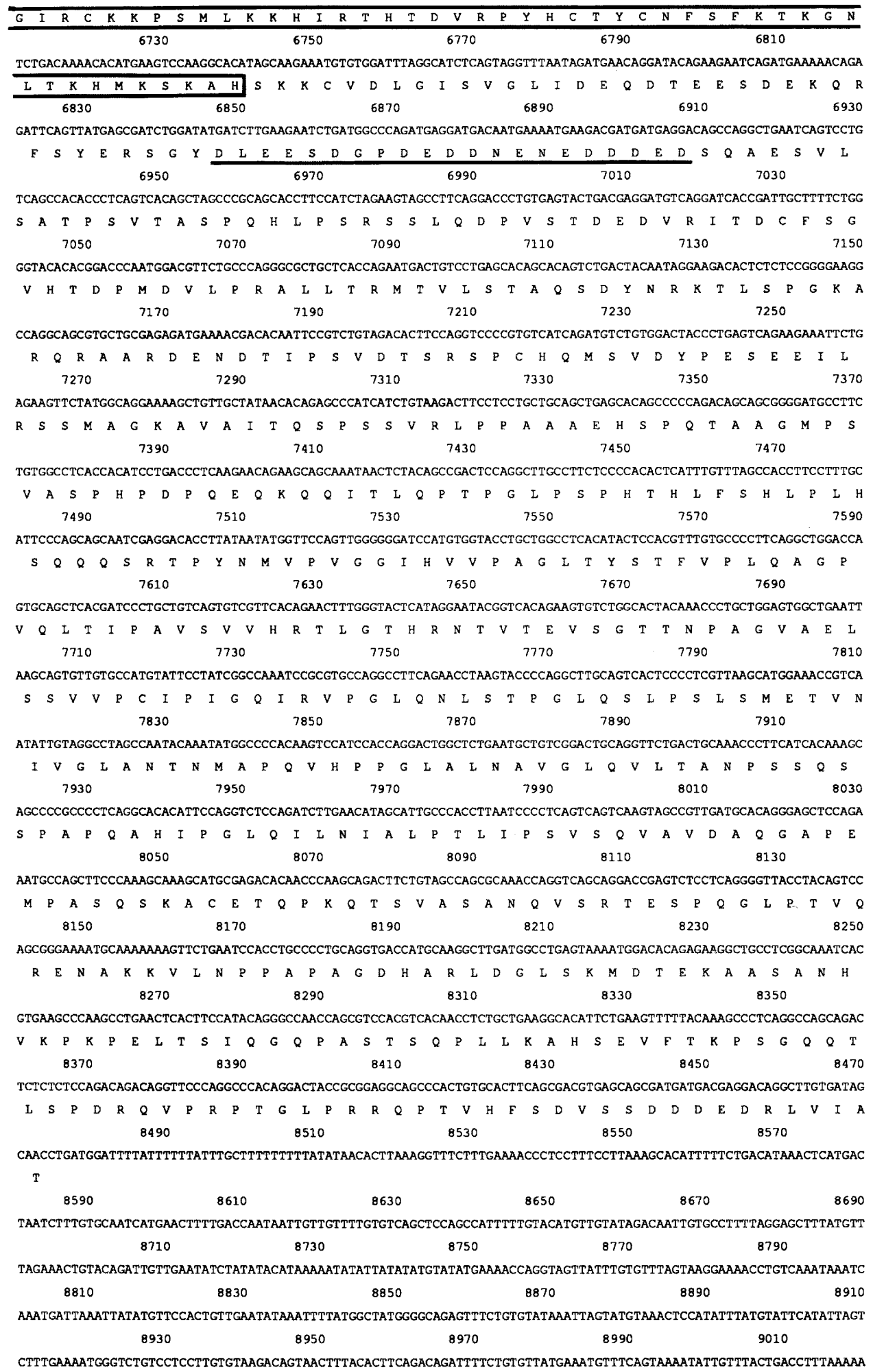

Figure 2. (continued)

using the $\mathrm{H}-2 \mathrm{~K}^{\mathrm{b}}$ probe and a 'minimal' $16-\mathrm{kD}$ C-Fin and a 23-kD N-Fin (MC-Fin and MN-Fin; Fig. 5C) fusion protein containing only the amino acids residues around the $\mathrm{Zn}$ finger motifs. The cDNA fragments used for fusion protein expression are shown in Figure 1. Because of the toxicity of MC-Fin in bacteria, we used in vitrotranslated protein to assay the DNA binding activity of this peptide. As shown in Figure 5C, DNA-binding activities of the in vitro-translated MC-Fin (lanes 1-4) and the bacteria-produced MN-Fin (lanes 5-8) are specific 


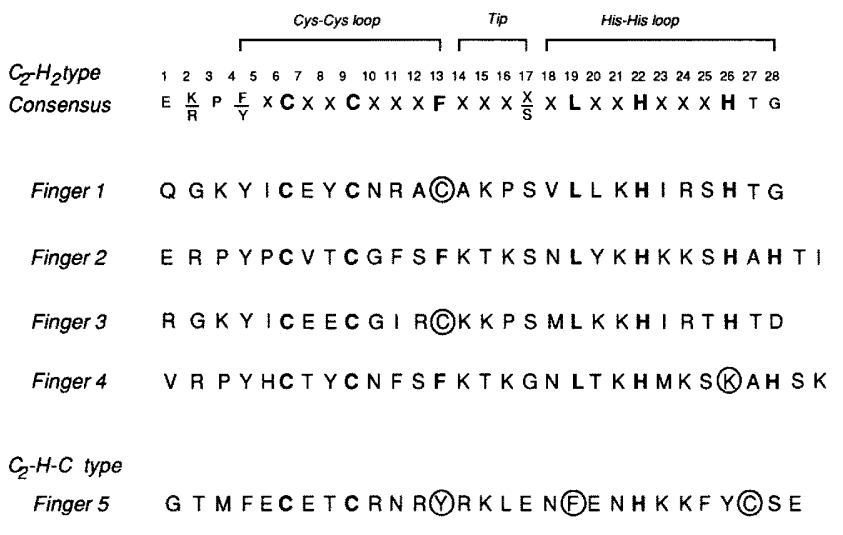

Figure 3. Comparison of the putative $\mathrm{Zn}$ finger motifs of PRDII-BF1. The consensus sequence of a $\mathrm{C}_{2}-\mathrm{H}_{2}-$ type $\mathrm{Zn}$ finger is presented on the top line with positions numbered for comparison. The boldface letters represent residues that are $>90 \%$ conserved, whereas the smaller letters indicate $>50 \%$ representation (according to Gibson et al. 1988). For PRDII-BF1 fingers, the boldface letters indicate conformity to the consensus; residues that deviate from the consensus are circled.

because they are competed by the $\mathrm{H}-2 \mathrm{~K}^{\mathrm{b}}$, but not an unrelated $(\mathrm{Hex})_{4}$, oligonucleotide (Keller and Maniatis 1988). Also, during the preparation of these fusion proteins, we found that they do not bind DNA after guanidine denaturation-renaturation steps unless the solution is supplemented with $10 \mu \mathrm{M} \mathrm{ZnSO}_{4}$ during dialysis. We conclude that each set of two $\mathrm{Zn}$ fingers is sufficient to bind specifically to the $\mathrm{H}-2 \mathrm{~K}^{\mathrm{b}}$ recognition sequence and that zinc is required for this binding activity.

To determine whether the two sets of two $\mathrm{Zn}$ fingers make the same DNA contacts, we carried out methyl- ation interference experiments with the $\mathrm{H}-2 \mathrm{~K}^{\mathrm{b}}$ probe. As shown in Figure 6, methylation of any 1 of the $4 \mathrm{G}$ residues on either strand of the $\mathrm{H}-2 \mathrm{~K}^{\mathrm{b}}$ sequence interferes with complex formation with either the C-Fin or N-Fin $\mathrm{Zn}$ fingers [cf. the bound fraction (lanes 4, 6, 10, and 12) to the free probe (lanes $3,5,9,11)]$. In the case of the C-Fin protein, methylation of the inner $3 \mathrm{Gs}$ seems to interfere with binding with equal efficiency, whereas only $50 \%$ of the complexes fail to form when the outside $\mathrm{G}$ is methylated. A very similar pattern of methylation interference is observed with the N-Fin protein. Therefore, we conclude that the contacts between each set of $\mathrm{Zn}$ fingers and the $\mathrm{H}-2 \mathrm{~K}^{\mathrm{b}}$ DNA recognition sequence are similar, if not identical.

\section{The PRDII-BF1 gene is inducible by virus and serum, but not by IFN- $a$ or IFN- $\beta$}

PRDII-BF1 binds to PRDII, a virus-inducible regulatory element of the IFN- $\beta$ gene promoter and to a site in the $\mathrm{H}-2 \mathrm{~K}^{\mathrm{b}}$ gene promoter that is required for maximal levels of induction by IFN- $\alpha / \beta$ (Baldwin and Sharp 1987). To determine whether the PRDII-BFl gene responds to either or both of these inducers, we analyzed the level of PRDII-BF1 mRNA in MG63 cells before and after induction with virus or IFN- $\alpha / \beta$. We find that PRDII-BFI mRNA is virus inducible, but with kinetics that differ significantly from those observed with IFN- $\beta$ mRNA (Fig. 7A). The level of IFN- $\beta$ mRNA peaks at $4 \mathrm{hr}$ after induction, and decreases to a low level by $16 \mathrm{hr}$. In contrast, an increase in the level of PRDII-BF1 mRNA is not observed until $8 \mathrm{hr}$ after virus infection; a maximum is reached after $16 \mathrm{hr}$ and persists through $30 \mathrm{hr}$ (Fig. 7A, lanes 1-8). The mRNA level remains high even after 60 hr of viral treatment, at which time the cells are no

A
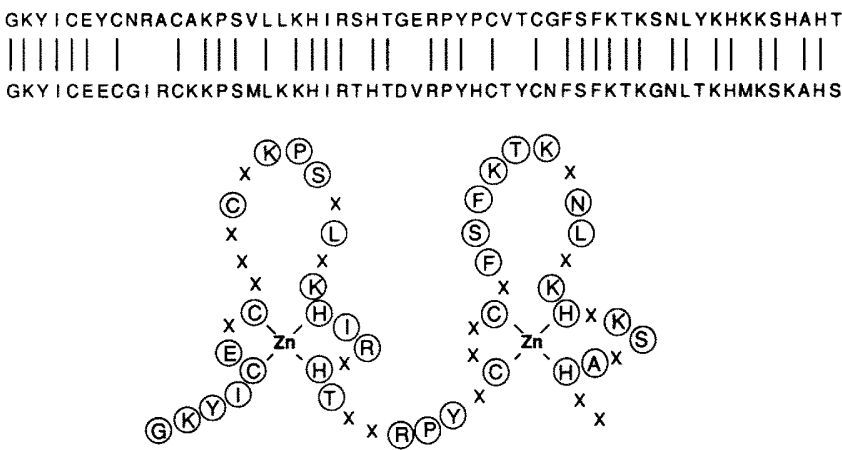

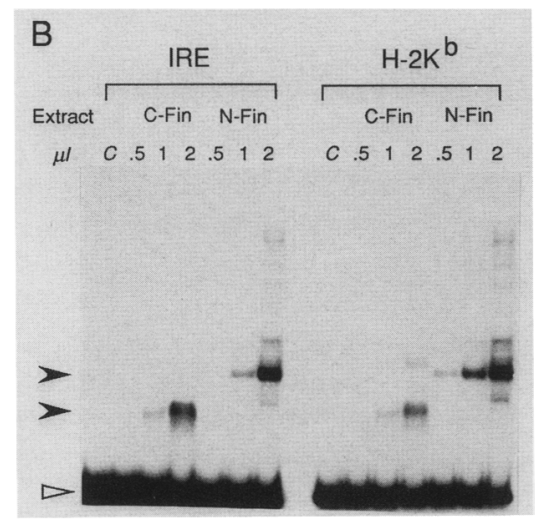

Figure 4. DNA binding specificity of the $\mathrm{Zn}$ finger motifs of PRDII-BF1. (A) Amino acid sequence comparison of the two sets of two $\mathrm{Zn}$ finger motifs. The amino acid sequences are aligned amino to carboxyl terminus with homologous amino acid residues indicated by vertical lines. Conserved amino acids residues between the two finger domains are circled and displayed below the sequence. The cysteine residue $(\mathrm{C})$ in both finger domains of PRDII-BFI is a phenylalanine residue in most other $\mathrm{Zn}$ fingers. The His-His loop of finger 2, drawn as a 5 amino acid loop to maximize the homology with finger 4, may altenatively form a 3 amino acid loop. $(B)$ Gel retardation assays with bacterial fusion proteins containing the amino- or carboxy-terminal ( $\mathrm{N}$-Fin, $\mathrm{C}$-Fin) $\mathrm{Zn}$ fingers. Increasing amounts of bacterial extracts prepared from cells expressing the $\mathrm{N}$ - or $\mathrm{C}$-Fin regions shown in Fig. 1B were mixed with labeled IRE or $\mathrm{H}-2 \mathrm{~K}^{\mathrm{b}}$ DNA probes and the complexes separated by gel electrophoresis. The IRE probe contained $50,000 \mathrm{cpm} / \mathrm{lane}$, and the $\mathrm{H}-2 \mathrm{~K}^{\mathrm{b}}$ probe $10,000 \mathrm{cpm} /$ lane. Because of apparent proteolytic activity in the extract, several DNA/protein complexes were detected; and only the major complex is indicated by arrowheads (left) (Fig. 6). 


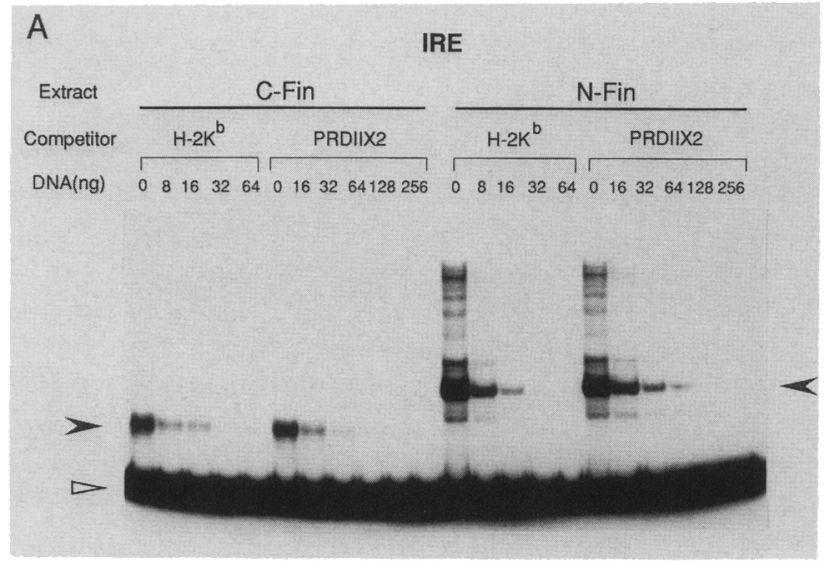

C

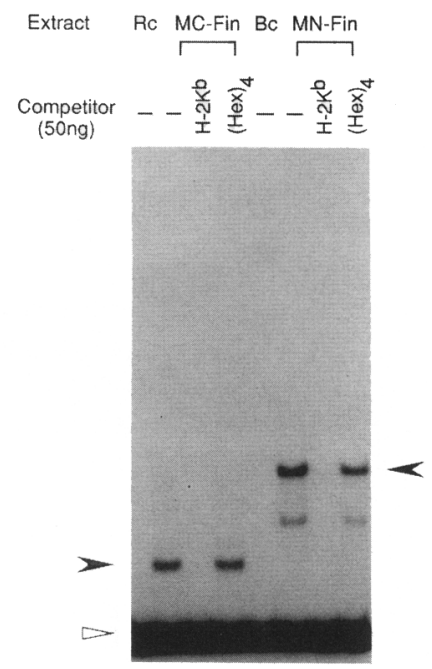

longer viable (data not shown). Comparison of the kinetics of IFN- $\beta$ and PRDII-BF1 induction reveals that the increase of PRDII-BF1 mRNA begins at a time when the level of IFN- $\beta$ mRNA starts to decrease (Fig. 7A). The unusually slow kinetics of virus induction of the PRDIIBF1 gene suggest that this gene is not responding to the same virus-inducible regulatory signals as the IFN- $\beta$ gene. Alternatively, the increase in PRDII-BF1 mRNA may be an indirect effect of virus induction.

We also carried out experiments to determine whether PRDII-BF1 mRNA is inducible by IFN- $\alpha / \beta$ and were unable to see an effect with $2000 \mathrm{U} / \mathrm{ml}$ IFNs for $16 \mathrm{hr}$ (data not shown). As a positive control we verified that the IFN-inducible human 6-16 gene was induced in parallel experiments (Friedman et al. 1984).

While carrying out control experiments for virus induction, we discovered that the level of PRDII-BF1 mRNA increases when cells are treated with $10 \%$ serum (Fig. 7B). Low levels of mRNA are detected prior to induction, rise to a peak at $2 \mathrm{hr}$ postinduction, and decline to the preinduction level after $10 \mathrm{hr}$ (Fig. 7B, lanes 1-5). The kinetics of serum induction of PRDII-BF1 are similar to those of other serum-responsive genes such as the

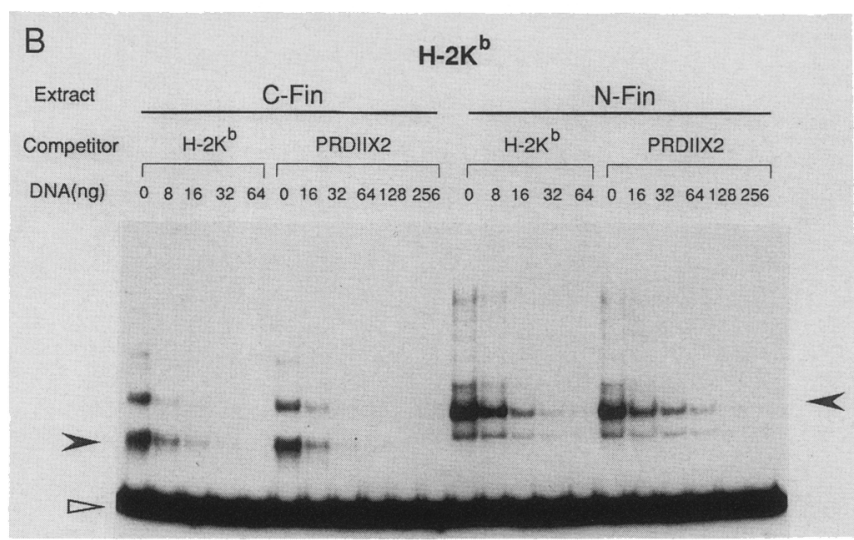

Figure 5. Competition binding experiments. (A) DNA complexes were prepared as described in Fig. 4 using labeled IRE DNA fragments, except that unlabeled DNA fragments were added as competitors. These competitors were synthetic oligonucleotides containing either two adjacent copies of PRDII (PRDIIX2) or one copy of $\mathrm{H}-2 \mathrm{~K}^{\mathrm{b}}$ element $\left(\mathrm{H}-2 \mathrm{~K}^{\mathrm{b}}\right.$; see Materials and methods). The amount of the oligonucleotides used for competition is specified in nanograms (ng). $B$ is the same as $A$, except that the $\mathrm{H}-2 \mathrm{~K}^{\mathrm{b}}$ DNA fragment was used as the probe. $(C)$ Gel retardation assay with fusion protein MC-Fin and MN-Fin. (Rc) Rabbit reticulocyte lysate control; MC-Fin is translated in vitro (NEN) and used directly in the binding assay. (Bc) bacteria control extract; MN-Fin is a bacteria-produced fusion protein. The competitors used are oligonucleotides containing either $\mathrm{H}-2 \mathrm{~K}^{\mathrm{b}}$ site as mentioned above or $(\mathrm{Hex})_{4}$, see text.

c-myc gene (Dean et al. 1986). Internal control $\gamma$-actin mRNA also increases slightly after serum induction, consistent with previous studies (Masibay et al. 1988).

\section{Nuclear localization of PRDII-BF1 protein shows that it is not $N F-\mathrm{\kappa} B$}

The three DNA-binding activities, PRDII-BF1, H2TF1 (Baldwin and Sharp 1987; 1988), and NF-кB (Lenardo and Baltimore 1989) specifically recognize the same set DNA sequences. They could be the same protein, different processed forms of one protein, or entirely different proteins. $\mathrm{H} 2 \mathrm{TFl}$ is a $120-\mathrm{kD}$ protein detected in nuclear extacts from a variety of cell types and was originally identified by its ability to bind to the $\mathrm{H} 2-\mathrm{K}^{\mathrm{b}}$ promoter (Baldwin and Sharp 1987; A. Baldwin, pers. comm.). NF-kB is a $45-50-\mathrm{kD}$ protein present in the cytoplasm of most cell types in a form that does not bind DNA, but its binding activity and nuclear localization can be induced by a variety of agents (Lenardo and Baltimore 1989). H2TF1 and NF-кB are clearly different proteins, as they display different methylation interference patterns (Baldwin and Sharp 1988) and they differ in mo- 


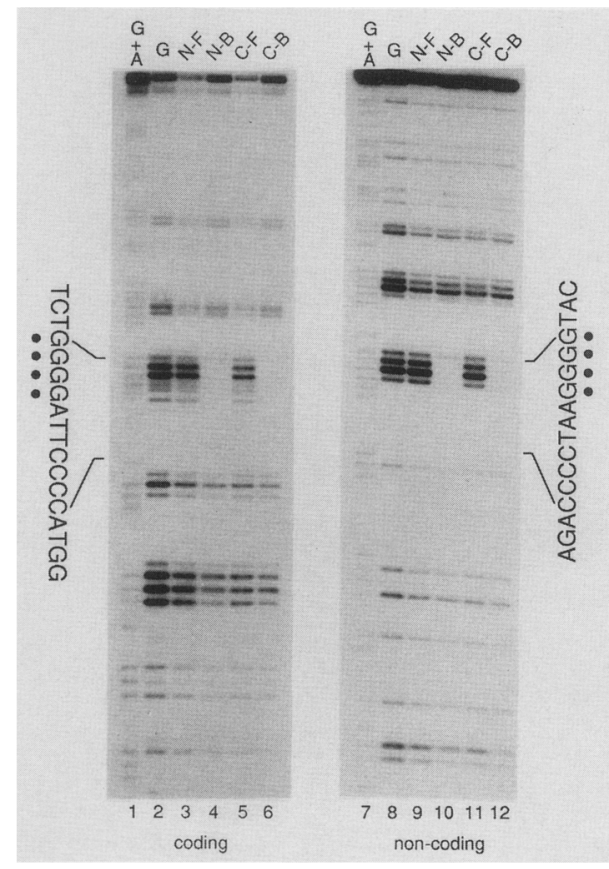

Figure 6. Methylation interference experiments with the $\mathbf{N}$ and C-Fin fusion proteins complexed with $\mathrm{H}-2 \mathrm{~K}^{\mathrm{b}}$ probe. (Left) The cleavage patterns on the coding strand of the probe; (right), the noncoding strand. Lanes $G+A$ and $G$ are probes with standard chemical sequencing reactions lanes. N-F and N-B are the cleavage patterns of free and bound $\mathrm{H}-2 \mathrm{~K}^{\mathrm{b}}$ probes of the gel retardation complexes when the N-Fin fusion protein is used. Lanes $C-F$ and $C-B$ are patterns of complexes with C-Fin. The sequences of the binding site are listed on either side of the autoradiograph. (O) Methylated nucleotides that interfere with binding.

lecular weight. In addition, H2TF1 DNA binding activity is ubiquitous, whereas that of NF- $\mathrm{kB}$ is restricted to mature $\mathrm{B}$ cells or must be induced in other cell types.

Although the predicted molecular weight of PRDII$\mathrm{BF} 1$ is considerably greater than that of NF- $\mathrm{KB}$, the possibility that NF- $\mathrm{KB}$ is generated by processing of the PRDII-BFl cannot be ruled out. Because NF-KB is located in the cytoplasm of most cell types, the processed form of PRDII-BF1 should display the same intracellular localization. To test this possibility, we raised rat polyclonal antibodies against different regions of PRDII-BF1 produced in bacteria and carried out immunofluorescent staining experiments. As shown in Figure 8, rat antiserum directed against the carboxy-terminal $\mathrm{Zn}$ finger region of PRDII-BF1 stains the nucleus of human MG63 cells. The same result was obtained with antiserum directed against the amino-terminal $\mathrm{Zn}$ finger region of PRDII-BF-1 (data not shown). We conclude that PRDII$\mathrm{BF} 1$ is not a precursor of NF-kB.

Additional evidence for this conclusion is provided by the results of Western blotting experiments which show that anti-PRDII-BF1 antisera detect two to three high molecular mass proteins $(250-290 \mathrm{kD})$ but do not detect proteins with molecular weight corresponding to that of NF- $\kappa B$ or of H2TF1 (data not shown). At present, it ap- pears that the three proteins are different. However definitive proof of this conclusion will require cloning the cDNAs encoding H2TF1 and NF-кB.

\section{Discussion}

We report the identification of PRDII-BF1, an unusual DNA-binding protein that specifically interacts with a sequence motif found in a number of different enhancers and promoters. We isolated a cDNA clone encoding PRDII-BF1 by screening a bacteriophage $\lambda$ expression cDNA library with PRDII, a virus-inducible regulatory element of the human IFN- $\beta$ gene. Similar sequences found in the promoter of the H2- $\mathrm{K}^{\mathrm{b}}$ gene and the HIV-1 enhancer were used previously to isolate cDNA clones that encode DNA-binding proteins designated MBP-1 (Singh et al. 1988; Baldwin et al., pers. comm.) and HIVEP1 (Maekawa et al. 1989). In addition to the IFN- $\beta$ and MHC promoters and the HIV-1 enhancer, the PRDII-BF1 protein binds specifically to the $\kappa B$ site of the Ig- $\kappa$ gene enhancer and to the SV40 enhancer core sequence (Singh et al. 1988).

Additional studies will be required to determine the function of PRDII-BF1. Potential roles for this protein are suggested by the observations that the level of PRDII-BFl mRNA is inducible by serum and virus. The kinetics of serum induction of PRDII-BF1 are similar to those of the c-myc oncogene (Dean et al. 1986). Because PRDII-BFI binds specifically to a sequence within the

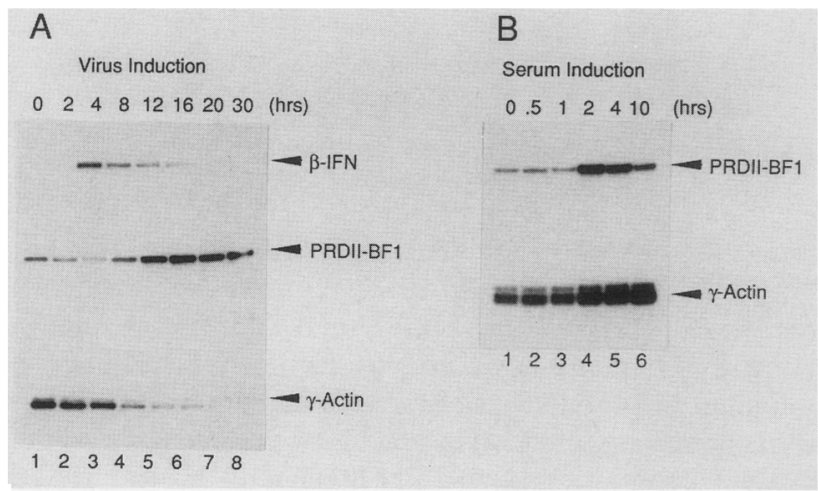

Figure 7. Virus and serum induction of PRDII-BF1 mRNA. (A) Virus-induction kinetics. Each lane contains $10 \mu \mathrm{g}$ of total RNA isolated from MG63 cells treated with Sendai virus in serum-free medium for the length of time indicated at top of each lane. The RNA samples were analyzed by RNase mapping (Zinn et al. 1983) using PRDII-BF1 and $\gamma$-actin hybridization probes (see Materials and methods). The protected PRDII-BFl, hIFN- $\beta$ and $\gamma$-actin probes are indicated by arrowheads (right). The specific activity of the $\gamma$-actin and IFN- $\beta$ probes was 50 times lower than that of the PRDII-BF1 probe. $(B)$ Serum induction kinetics. Each lane contains $10 \mu \mathrm{g}$ of total RNA of MG63 cells treated with serum for $0-10 \mathrm{hr}$ las shown at top of each lane). The RNA samples were analyzed by RNase mapping with PRDII-BF1 and $\gamma$-actin hybridization probes. The protected PRDII-BF1 and $\gamma$-actin probes are indicated by arrowheads (right). The relative specific activities of the probes were as indicated in $A$. 


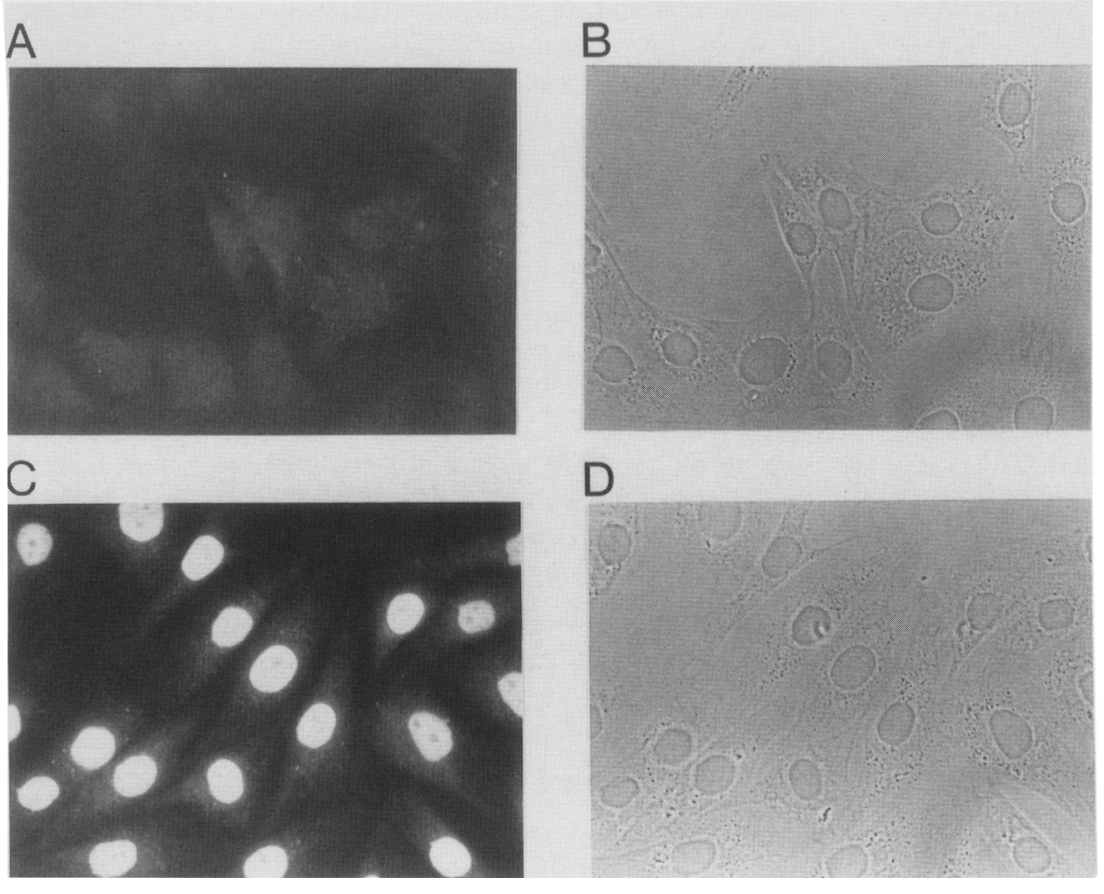

Figure 8. Nuclear localization of PRDII-BF1 protein in human MG63 cells. Immunofluorescent staining with rat preimmune and anti-C-Fin antibodies. $(A)$ Preimmune serum; $(C)$ anti-C-Fin anti-serum. $(B$ and $D)$ The phase microscopic photographs of the cells in $A$ and $C$, respectively.
$\mathrm{H} 2-\mathrm{K}^{\mathrm{b}}$ gene promoter, we carried out experiments to determine whether class I major histocompatibility genes (HLA) are serum inducible. We found that the level of HLA mRNA increases by approximately threefold after serum induction, with kinetics that are slightly slower than those of PRDII-BF1 (data not shown). Although these observations are suggestive, additional studies are required to determine whether PRDII-BF1 plays a role in the serum induction of HLA genes.

The PRDII-BF1 gene is also induced by virus but with kinetics that are unlike those of any previously described virus-inducible gene. Virus induction of the IFN- $\beta$ gene leads to high levels of mRNA by $4 \mathrm{hr}$, and decreases rapidly and is barely detectable at $16 \mathrm{hr}$. In contrast, maximal levels of PRDII-BF1 mRNA are not detected until $16 \mathrm{hr}$ after virus induction. At present, there is no direct evidence that PRDII-BF1 plays a role in the virus induction of the IFN- $\beta$ gene.

\section{The structure of PRDII-BF1}

The amino acid sequence of PRDII-BFl reveals two unique features. First, it is the largest sequence-specific DNA-binding protein so far identified. This protein has a molecular mass of $298 \mathrm{kD}$, and its mRNA is $\sim 9500$ nucleotides in length. Second, PRDII-BF1 contains two widely separated sets of $\mathrm{Zn}$ fingers that bind to the same DNA sequence.

The $\mathrm{Zn}$ fingers of PRDII-BF1 are of the $\mathrm{C}_{2}-\mathrm{H}_{2}$ type originally identified in the transcription factor TFIIIA and subsequently shown to be present in a large number of other DNA-binding proteins (for review, see Klug and Rhodes 1987; Gibson et al. 1988). Isolated Zn finger motifs of this class were shown to be sufficient for spe- cific DNA binding of the transcription factors TFIIIA and SP1 (Smith et al 1984; Kadonaga et al 1987). Steroid hormone receptors contain a different class of $\mathrm{Zn}$ fingers, which consist of $\mathrm{C}_{4}$ or $\mathrm{C}_{5}$ units /for review, see Berg 19891. As with the $\mathrm{C}_{2}-\mathrm{H}_{2}$ type of $\mathrm{Zn}$ finger, mutations within the $\mathrm{Zn}$ finger of the glucocorticoid receptor abolish DNA binding activity.

In this paper we show that the DNA binding activities of the two fusion proteins N-Fin and C-Fin, derived from PRDII-BF1 cDNA, require the $\mathrm{Zn}$ finger motif, because minimum fusion proteins $\mathrm{MN}$-Fin and MC-Fin containing only the Zn finger domains are sufficient for specific DNA interactions. The observation that zinc is required for the binding activities of the two $\mathrm{Zn}$ finger domains of PRDII-BF1 provides further evidence that the $\mathrm{Zn}$ fingers are functional DNA-binding domains. The zinc requirement for the DNA binding activity of other $\mathrm{C}_{2}-\mathrm{H}_{2}$ and $\mathrm{C}_{\mathrm{x}}$-type $\mathrm{Zn}$-finger proteins has been reported (Kadonaga et al 1987; Freedman et al. 1988). We have not identified a function for the putative $\mathrm{Zn}$ finger domain located at amino acids 955-982; however, we have verified that it is not required for the binding to the $\mathrm{H}-2 \mathrm{~K}^{\mathrm{b}}$ site (data not shown).

Recent molecular modeling (Berg 1988; Gibson et al. 1988) and two-dimensional nuclear magnetic resonance (NMR) (Lee et al. 1989; Parraga et al. 1989) studies have led to a proposal for the three dimensional structure of $\mathrm{C}_{2}-\mathrm{H}_{2}$-type fingers. In this structure, the Cys-Cys loop is configured in an antiparallel $\beta$-sheet that is followed by a sharp right turn at the tip and then a helical region through the His-His loop. The $\beta$-sheet and helical regions are joined at the base of the structure through tetrahedrally coordinated zinc. The helical region, which contains a high density of basic and polar amino acids on 
one face, may contact DNA in the major groove. Further studies will be necessary to determine which aspect of this structure is required for specific protein-DNA interactions.

A comparison between the two sets of $\mathrm{Zn}$ fingers of PRDII-BF1 may provide insights to the question of specificity, because these regions bind to the same DNA sequence with virtually indistinguishable affinities and methylation interference patterns. An interesting feature shared by both pairs of fingers is the identity of the 4 amino acids immediately adjacent to the amino-terminal cysteine of the first fingers (Fig. 4A). Only the tyrosines at position 4 fit the consensus $\mathrm{E}-(\mathrm{K} / \mathrm{R})-\mathrm{P}-(\mathrm{Y} / \mathrm{F})-\mathrm{X}$ (Gibson et al. 1988). Thus, it is possible that the remaining 3 amino acids play a role in the specific recognition of PRDII. In fact, the residue immediately adjacent to this cysteine in the yeast transcription factor HAPl is required for specific DNA binding (L. Guarente, pers. comm.).

Amino acid residues in the His-His knuckle regions of the PRDII-BF $1 \mathrm{Zn}$ fingers are compatible with the formation of a helical region in the model structure. The high percentage of identical residues in the 1-3 and 2-4 pairs in this region suggest a role in specific proteinDNA interaction. The corresponding region of steroid hormone receptors / the second Cys-Cys knuckle of the first finger) has been shown to play a critical role in DNA binding specificity (Danielsen et al.1989; Mader et al. 1989; Umesono and Evans 1989). The pairwise conservation of amino acid sequence in the PRDII-BF1 knuckles extends into the tip regions of both pairs of fingers, suggesting that these residues may also be involved in DNA recognition.

\section{Proteins that bind to more than one DNA site}

PRDII-BF1 is the only DNA-binding protein thus far reported that contains two widely separated pairs of $\mathrm{Zn}$ fingers that bind to the same DNA sequence. Many $\mathrm{Zn}$ finger proteins contain multiple $\mathrm{Zn}$ fingers, but they are usually present as a contiguous set. For example, the transcription factor TFIIIA has nine fingers that interact with a repeated sequence motif within the 5S RNA gene. The Drosophila genes serendipity $\delta$ and hunchback do contain separate clusters of $\mathrm{Zn}$ finger motifs, but the ability of these motifs to bind DNA has not been demonstrated (Vincent et al. 1985; Tautz et al. 1987).

Both of the eukaryotic DNA-binding proteins C/EBP (Landschulz et al. 1988) and HAPl (Pfeifer at al. 1987) are able to bind to two different DNA recognition sequences. However, in both of these cases it appears that a single DNA-binding motif recognizes both sequences, so the proteins cannot bind to two DNA sites simultaneously. DNA-binding proteins that can bind to two different sites at the same time are the bacteriophage $\lambda$ integrase protein (Int; Moitoso de Vargas et al. 1988) and the bacteriophage Mu transposase (MuA; Mizuuichi and Mizuuichi 1989). Both of these proteins have two different DNA-binding domains, and they are involved in the assembly of multicomponent protein-DNA com- plexes required for DNA insertion and excision. The activity of these complexes depends on the presence of additional factors and on the arrangements of the DNAbinding sites.

PRDII-BF1 is clearly different from these prokaryotic proteins in that it can potentially bind to two 'identical' DNA sequences at the same time, using two similar DNA-binding domains located at opposite ends of the protein. Like Int and MuA, PRDII-BFI could therefore be involved in the assembly of a multicomponent DNAprotein complex by binding simultaneously to widely separated recognition sequences. Alternatively, PRDIIBFl could bind to the same DNA sequence on different choromosomes to bring two different promoters to a common site within the nucleus. In either case, further studies of this unusual DNA-binding protein could provide novel insights to the mechanisms involved in regulating the assembly of eukaryotic transcription initiation complexes.

\section{Materials and methods}

cDNA library screening

A $\lambda$ gtll expression library was screened with end-labeled PRDIIX2 oligonucleotides by the procedure developed by Singh et al. (1988). For DNA hybridization screening, $2 \times 10^{6} \mathrm{cpm} / \mathrm{ml}$ of random oligonucleotide-primed DNA probe was used to probe cDNA libraries as described by Maniatis et al. (1982).

\section{DNA sequencing}

All cDNA phage clones were subcloned into the polylinker of pSP73 plasmid (Promega). These fragments were further subcloned by convenient restriction sites or BAL-31 deletions. Sequencing reactions were performed by double-stranded sequencing with either SP6 or T7 promoter primers using Sequenase (US Biochemicals) or Taq polymerase for difficult regions (Stratagene). For most regions of the DNA, both strands were sequenced.

\section{Induction and RNase mapping}

Cells were serum-starved for $12 \mathrm{hr}$ and then incubated in fresh media containing $10 \%$ serum for serum-induced cells or fresh serum-free media for mock-induced cells. Virus induction was performed with Sendai virus in serum-free medium essentially as described by Zinn et al. (1983). RNase mapping experiments were performed as described by Zinn et al. (1983), using the following probes: pSP64 Huy-actin (Enoch et al. 1986) which protects 143 nucleotides of human $\gamma$-actin mRNA to serve as an internal control; pSP73 $\lambda$ G3.4 1AccI-del, which contains an EcoRI-AccI fragment of $\lambda \mathrm{G} 3.4 \mathrm{cDNA}$ clone and protects 185 nucleotides of PRDII-BF1 mRNA; and pSP645'IFN, which protects 277 nucleotides of the human IFN- $\beta$ mRNA (Zinn et al. 1983).

\section{Gel retardation and methylation interference}

Probes used for gel retardation assays were IRE (Keller and Maniatis 1988) and H-2Kb DNA fragments (shown below), first cloned in the polylinker of pSP73 (BgIII and BamHI sites), and then cut out by BgIII and XhoI restriction enzymes and end-labled with Klenow. The sequence of the $\mathrm{H}-2 \mathrm{~K}^{\mathrm{b}}$ oligonucleotide used as competitor is: 


\section{GATCCTCTGGGGATTCCCCATGGA} GAGACCCCTAAGGGGTACCTCTAG

and the sequence of PRDIIX2 oligonucleotides is

\section{GATCTGTGGGAAATTCCGTGGGAAATTCCG ACACCCTTTAAGGCTCCCTTTAAGGCCTAG}

(Fan and Maniatis 1989). Bacterial extracts were incubated with either $50,000 \mathrm{cpm}(\sim 1 \mathrm{ng})$ IRE probe or $10,000 \mathrm{cpm} / \sim 0.2 \mathrm{ng}$ ) $\mathrm{H}-2 \mathrm{~K}^{\mathrm{b}}$ probe at $300^{\circ} \mathrm{C}$ for $20 \mathrm{~min}$ in a $25-\mu \mathrm{l}$ reaction containing $10 \mathrm{~mm}$ Tris- $\mathrm{HCl}(\mathrm{pH} 7.9), 50 \mathrm{~mm} \mathrm{NaCl}, .5 \mathrm{~mm}$ EDTA, $1 \mathrm{~mm}$ DTT, and $10 \%$ (vol/vol) glycerol. Samples were then electrophoresed on a $4.5 \%$ polyacrylamide Tris-glycine gel (Singh et al. $1988)$ at $4^{\circ} \mathrm{C}$ and $100 \mathrm{~V} / \mathrm{cm}$ for $3 \mathrm{hr}$. Methylation interference was carried out as described in Lenardo et al. (1989).

\section{Bacteria expression system and extract}

The bacteriophage $T 7$ expression system was adapted for the production of the fusion proteins (Studier and Moffatt 1986). DNA fragments containing portions of the PRDII-BF1-coding sequence were cloned into vectors containing $\mathrm{T} 7$ promoter. These plasmids were then transformed into the bacteria strain BL21(DE3), which contains the T7 RNA polymerase gene under Lac UV5 promoter control. Transformed bacteria were induced with $0.4 \mathrm{mM}$ IPTG at $\mathrm{OD}_{600}=0.4$ for $1 \mathrm{hr}$ and harvested. Extracts were prepared essentially by the procedures of Gual et al. (1987), except that $10 \mathrm{~mm} \mathrm{ZnSO}_{4}$ was included in each step, and, $6 \mathrm{M}$ guanidine- $\mathrm{HCl}$ was used as denaturant instead of urea.

\section{Immunofluorescent staining}

Indirect immunofluorescence staining experiments were carried out with rat anti-C-Fin antiserum, using methods described by Munro and Pelham (1987). Rat preimmune or antiC-Fin antisera were used as the first antibodies, and the FTICconjugated anti-rat $\mathrm{Ab}$ (Cappel) as the second antibody.

\section{Acknowledgments}

We thank J. Knopf for kindly providing an excellent HL-60 cDNA library and J. Wozney for help in amino acid sequence comparisons. We also thank $T$. Learned for technical assistance, S. Abmyr and A. Ephrussi for many suggestions on the protein work, and A. Baldwin, K. LeClair, H. Singh, and P. Sharp for sharing DNA sequence information prior to publication. This work is supported by a National Institutes of Health grant (AI20642) to T.M.

\section{References}

Baldwin, A.S. and P.A. Sharp. 1987. Binding of a nuclear factor to a regulatory sequence in the promoter of the mouse $\mathrm{H}-2 \mathrm{~K}^{\mathrm{b}}$ class I major histocompatibility gene. Mol. Cell. Biol. 7: 305-313.

- 1988. Two transcription factors, NF-kB and H2TF1, interact with a single regulatory sequence in the class I major histocompatibility complex promoter. Proc. Natl. Acad. Sci. 85: 723-727.

Berg, J.M. 1988. Proposed structure for the zinc-binding domains from transcription factor IIIA and related proteins. Proc. Natl. Acad. Sci. 85: 99-102.

- 1989. DNA-binding specificity of steroid receptors. Cell 57: 1065-1068.

Blanar, M.A., A.S. Baldwin, Jr., R.A. Flavell, P.A. Sharp. 1989. A gamma-interferon-induced factor that binds the interferon response sequence of the $\mathrm{MHC}$ class I gene, $\mathrm{H}-2 \mathrm{~K}^{\mathrm{b}}$. EMBO. I. 8: $1139-1144$.

Clark, L., R.M. Pollock, and R.T. Hay. 1988. Identification and purification of EBP1: A HeLa cell protein that binds to a region overlapping the 'core' of the SV40 enhancer. Genes Dev. 2: $991-1002$.

Clark, L. and R.T. Hay. 1989. Sequence requirement for specific interaction of an enhancer binding protein (EBP1) with DNA. Nucleic Acids Res. 17: 499-516.

Danielsen, M., L. Hinck, and G.M. Ringold. 1989. Two amino acids within the knuckle of the first two $\mathrm{Zn}$ fingers specify DNA response element activation by the glucocorticoid receptor. Cell 57: 1131-1138.

Dean, M., R.A. Levine, W. Ran, M.S. Kindy, G.E. Sonenshein and J. Campisi. 1986. Regulation of c-myc transcription and mRNA abundance by serum growth factors and cell contact. J. Biol. Chem. 261: 9161-9166.

DeMaeyer, E. and J. DeMaeyer-Guinard. 1988. Interferons and other regulatory cytokines. John Wiley and Sons, New York.

Enoch, T., K. Zinn, and T. Maniatis. 1986. Activation of the human $\beta$-interferon gene requires an interferon-inducible factor. Mol. Cell. Biol. 6: 801-810.

Evans, R.M. and S.M. Hollenberg. 1988. Zinc fingers: Gilt by association. Cell 52: 1-3.

Fan, C.-M., and T. Maniatis. 1989. Two different virus-inducible elements are required for human $\beta$-IFN gene regulation. EMBO 6: 101-110.

Freedman, L.P., B.F. Luisi, Z.R. Korszun, R. Basavappa, P.B. Sigler, and K.R. Yamamoto. 1988. The function and structure of the metal coordination sites within the glucocorticoid receptor DNA-binding domain. Nature 334: 543-545.

Fried, M. and D.M. Crothers. 1981. Equilibrium and kinetics of Lac repressor operator interactions by polyacrylamide gel electrophoresis. Nucleic Acids Res. 9: 6505-6525.

Friedman, R.L., R.P. Manly, M. Mamahon, I.M. Kerr, and G.R. Stark. 1984. Transcriptional and posttranscriptional regulation of interferon-induced gene expression in human cells. Cell 38: 745-755.

Fujita,T., J. Sakakibara, Y. Sudo, M. Miyamoto, Y. Kimura, and T. Taniguchi. 1988. Evidence for a nuclear factor(s), IRF-1, mediating induction and silencing properties to human IFN- $\beta$ gene regulatory elements. 7: 3397-3405.

Fujita, T., M. Miyamoto, Y. Kimura, J. Hammer, and T. Taniguchi. 1989a. Involvement of a cis-element that binds an H2TF-1/NF- $\mathrm{kB}$-like factor $(\mathrm{s})$ in the virus-induced interferon$\beta$ gene expression. Nucleic Acids Res. 17: 3335-3346.

Fujita, T., Y. Kimura, M. Miyamoto, E.L. Barsoumian, and T. Taniguchi. 1989b. Induction of endogeneous IFN- $\alpha$ and IFN- $\beta$ genes by a regulatory transcription factor, IRF-1. $\mathrm{Na}$ ture 337: 270-272.

Gibson, T.J., J.P.M. Postma, R.S. Brown, and P. Argos. 1988. A model for the tertiary structure of the 28 residue DNAbinding motif 'zinc finger' common to many eukaryotic transcriptional regulatory proteins. Protein Eng. 2: 209218.

Goodbourn, S. and T. Maniatis. 1988. Overlapping positive and negative regulatory domains of the human $\beta$-interferon gene. Proc. Natl. Acad. Sci. 85: 1447-1451.

Goodbourn, S., K. Zinn, and T. Maniatis. 1985. Human $\beta$-interferon gene expression is regulated by an inducible enhancer element. Cell 41: 509-520.

Gual, U., E. Seifert, R. Schuh, and H. Jackle. 1987. Analysis of Krüppel protein distribution during early Drosophila development reveals posttranscriptional regulation. Cell 50: 639-647.

Kadonaga, J.T., K.R. Carner, F.R. Masiarz, and R. Tjian. 1987 
Isolation of cDNA encoding transcription factor $\mathrm{Spl}$ and functional analysis for the DNA-binding domain. Cell 51: $1079-1090$.

Keller, A. and T. Maniatis. 1988. Identification of an inducible factor that binds to a positive regulatory element of the human $\beta$-interferon gene. Proc. Natl. Acad. Sci. 85: 33093313.

Klug, A. and D. Rhodes. 1987. 'Zinc fingers': A novel protein motif for nucleic acid recognition. Trends Biochem Sci. 12: 464-469.

Kozak, M. 1987. An anlysis of $5^{\prime}$-noncoding sequences from 699 vertebrate messenger RNAs. Nucleic Acids Res. 15: 8125, 8148.

Landschulz, W.H., P.F. Johnson, E.Y. Adashi, B.J. Graves, and S.L. McKnight. 1988. Isolation of a recombinant copy of the gene encoding C/EBP. Genes Dev. 2: 786-800.

Lee, M.S., G.P. Gippert, K.W. Soman, D.A. Case, and P.E. Wright. 1989. Three-dimensional structure of a single zinc finger DNA-binding domain. Science 245: 635-637.

Lenardo, M.J., A. Kuang, A. Gifford, and D. Baltimore. 1988. NF- $\mathrm{B}$ purification from bovine spleen: nucleotide stimulation and binding site specificity. Proc. Natl. Acad. Sci. 85: $8825-8829$.

Lenardo, M. and D. Baltimore. 1989. NF-кB: A pleiotropic mediator of inducible and tissue-specific gene control. Cell 58: $227-229$.

Lenardo, M., C.-M. Fan, T. Maniatis, and D. Baltimore. 1989. The involvement of NF- $\mathrm{BB}$ in $\beta$-interferon gene regulation reveals it role as widely inducible mediator of signal transduction. Cell 57: 287-294.

Mader, S., V. Kumar, H. de Verneuil, and P. Chambon. 1989. Three amino acids of the oestrogen receptor are essential to its ability to distinguish an oestrogen from a glucocorticoid responsive element. Nature 338: 271-274.

Maekawa, T., H. Sakura, T. Sudo, and S. Ishii. 1989. Putative metal finger structure of the human immunodeficiency virus type 1 enhancer binding protein HIV-EP1. I. Biol. Chem. 264: 14591-14593.

Maniatis, T., E.F. Fritsch, and J. Sambrook. 1982. Molecular cloning: A laboratory manual. Cold Spring Harbor Laboratory, Cold Spring Harbor, New York.

Maniatis, T. 1988. Mechanism of human $\beta$-interferon gene regulation. In Harvey Lectures. vol. 82, pp. 71-104. Alan R. Liss, Inc., New York.

Masibay, A.S., P.K. Qasba, D.N. Sengupta, G.P, Damewood, and T. Sreevalsan. 1988. Cell-cycle-specific and serum-dependent expression of gamma-actin mRNA in swiss mouse 3T3 cells. Mol. Cell. Biol. 8: 2288-2294.

Miyamoto, M., T. Fujita, Y. Kimura, M. Maruyama, H. Harada, Y. Sudo, T. Miyata, and T. Taniguchi. 1988. Regulated expression of a gene encoding a nuclear factor, IRF-1, that specifically binds to IFN- $\beta$ gene regulatory elements. Cell 54: 903-913.

Mizuuchi, M. and K. Mizuuchi. 1989. Efficient Mu transposition requires interaction of transposase with a DNA sequence at the $\mathrm{Mu}$ operator: Implications for regulation. Cell 58: $399-408$

Moitoso de Vargas, L., C.A. Pargellis, N.M. Hasan, E.W. Bushman, and A. Landy. 1988. Autonomous DNA-binding domains of $\lambda$ integrase recognize two different sequence families. Cell 54: 923-929.

Munro, B.S. and H.R.B. Pelham. 1987. A C-terminal signal prevents secretion of luminal ER proteins. Cell 48: 899.

Parraga, G., S.J. Horvath, A. Eisen, W.E. Taylor, L. Hood, E.T. Young, and R.E. Klevit. 1989. Zinc-dependent structure of a single-finger domain of yeast ADR1. Science 241: 14891492.

Pfeifer, K., T. Prezant, and L. Guarente. 1987. Yeast HAP1 activator binds to two upstream activation sites of different sequence. Cell 49: 19-27.

Polites, H.G. and K.R. Marotti. 1986. A step-wise protocol for cDNA synthesis. BioTechniques 4: 514-520.

Ptashne, M. 1988. How eukaryotic transcriptional activators work. Nature 335: 683-689.

Shaw, G. and R. Kamen. 1986. A conserved AU sequence from the $3^{\prime}$-untranslated region of GM-CSF mRNA mediates selective mRNA degradation. Cell 46: 659-667.

Singh, H., J.H. LeBowitz, A.S. Baldwin, and P.A. Sharp. 1988. Molecular cloning of an enhancer binding protein: Isolation by screening of an expression library with a recognition site probe. Cell 52: 415-423.

Smith, D.R., I.J. Jackson, and D.D. Brown. 1984 Domains of the positive transcription factor specific for the Xenopus $5 \mathrm{~S}$ gene. Cell 37: 645-652.

Studier, F.W. and B. Moffatt. 1986. Use of bacteriophage T7 polymerase to direct selective high-level expression of cloned genes. J. Mol. Biol. 189: 113-130.

Tautz, D., R. Lehmann, H. Schnurch, R. Schuh, E. Seifert, A. Kienlin, K. Jones, and H. Jackle. 1987. Finger protein of novel structure encoded by hunchback, a second member of the gap class of Drosophila segmentation genes. Nature 327: $383-389$.

Umesono, K. and R.M. Evans. 1989. Determinants of target gene specificity for steroid /thyroid hormone receptors. Cell 57: 1139-1146.

Vincent, A., H.V. Colot, and M. Rasbash. 1985. Sequence and structure of the serendipity locus of Drosophila melanogaster. J. Mol. Biol. 186: 149-166.

Vinson, C.R., K.L. LaMarco, P.F. Johnson, W.H. Landschulz, S.L. McKnight. 1988. In situ detection of sequence-specific DNA-binding activity specified by a recombinant bacteriophage. Genes Dev. 2: 801-806.

Visvanathan, K.V. and S. Goodbourn. 1989. Double-stranded RNA activates binding of NF- $\mathrm{KB}$ to an inducible element in the human $\beta$-interferon promoter. EMBO J. 8: 1129-1138.

Zinn, K., D. DiMaio, and T. Maniatis. 1983. Identification of two distinct regulatory regions adjacent to the human $\beta$-interferon gene. Cell 34: 865-879. 


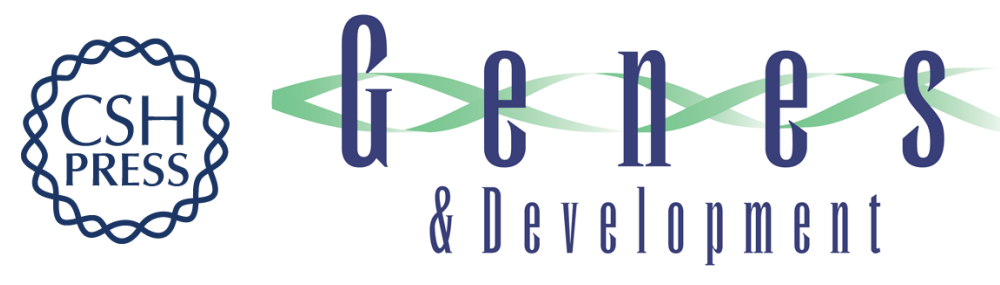

\section{A DNA-binding protein containing two widely separated zinc finger motifs that recognize the same DNA sequence.}

C M Fan and T Maniatis

Genes Dev. 1990, 4:

Access the most recent version at doi:10.1101/gad.4.1.29

References This article cites 51 articles, 14 of which can be accessed free at:

http://genesdev.cshlp.org/content/4/1/29.full.html\#ref-list-1

License

Email Alerting

Service right corner of the article or click here.

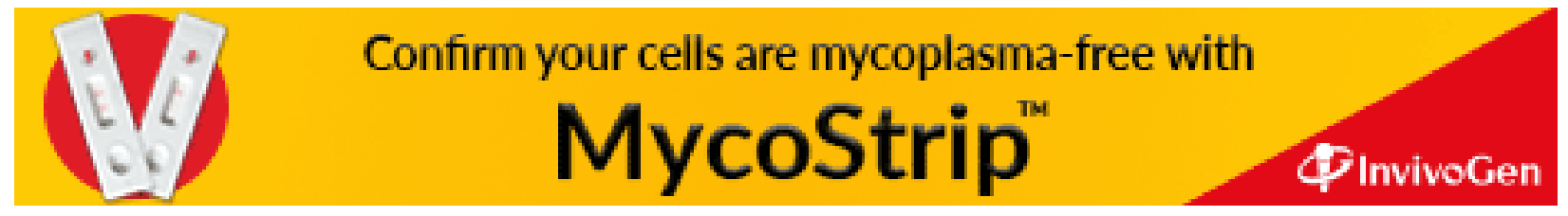

